\title{
Submandibular Gland Carcinoma
}

National Cancer Institute

\section{Source}

National Cancer Institute. Submandibular Gland Carcinoma. NCI Thesaurus. Code C8396.

A carcinoma that arises from the submandibular gland. Representative examples include mucoepidermoid carcinoma, adenoid cystic carcinoma, and carcinoma ex pleomorphic adenoma. 